\title{
Motion in Leibniz's Middle Years: A Compatibilist Approach
}

\author{
STEPHEN PURYEAR
}

One bone of contention among Leibniz scholars concerns the status of the corporeal world in the philosophy of Leibniz's 'middle years' (roughly, the I680s and I690s). According to one prominent tradition, Leibniz espoused essentially the same perspective during this period that we find expressed more overtly in such later writings as the Monadology and the correspondences with De Volder and Des Bosses. ${ }^{1}$ That is, he was a kind of phenomenalist, in that he accorded to bodies the status of phenomena or appearances, and an idealist, in that he proposed to reduce the whole of the corporeal realm to immaterial substances and their states. Of late, however, an increasing number of scholars have raised doubts about this traditional reading. ${ }^{2}$ On their view, it was not immaterial souls or monads but rather corporeal substances, understood in Aristotelian fashion as composites of form and matter, which the Leibniz of the middle years placed at the foundation of his ontology; and so as one who embraced the existence

1 See, e.g. Robert C. Sleigh, Jr., Leibniz and Arnauld: A Commentary on Their Correspondence [Leibniz and Arnauld] (New Haven: Yale University Press, I990); Robert M. Adams, Leibniz: Determinist, Theist, Idealist (New York: Oxford University Press, I994), Part III. The following abbreviations, in addition to those listed at the front of this volume, are used in this chapter: $\mathrm{C}=$ Opuscules et fragments inédits de Leibniz, ed. L. Couturat (Paris: Presses Universitaires de France, I903; repr. Hildesheim: Olms, I966); DM = Discours de métaphysique, cited by section number; $\mathrm{H}=$ Theodicy, trans. E. M. Huggard (LaSalle, IL: Open Court, I985).

2 See, e.g. C. D. Broad, Leibniz: An Introduction (New York: Cambridge University Press, I975); Daniel Garber, 'Leibniz and the Foundation of Physics: The Middle Years', in Kathleen Okruhlik and James Brown (eds.), The Natural Philosophy of Leibniz (Dordrecht: Reidel, I985), 27-I30; Samuel Levey, 'Leibniz on Precise Shapes and the Corporeal World' ['Precise Shapes'], in Donald Rutherford and J.A. Cover (eds.), Leibniz: Nature and Freedom (New York: Oxford University Press, 2005), 69-94; Daniel Garber, Leibniz: Body, Substance, Monad [Leibniz] (New York: Oxford University Press, 2009). 
of real and irreducibly material beings, he was neither a phenomenalist nor an idealist but a realist.

For all their differences, proponents of both these readings agree on an important point: they agree that the relevant texts of the middle years are at least largely consistent, and that Leibniz can therefore be viewed as having a single, consistent view of the matter during this period. Others, however, have raised doubts about the plausibility of any such 'compatibilist' approach. As they see it, Leibniz's claims about the status of body are not at all compatible. The writings of the middle years instead reveal the simultaneous presence of two competing strands in his thought, the one a phenomenalist and idealist strand, the other a realist strand. Since according to them Leibniz expressed no clear preference for the one strand over the other, and since the incompatibility of these strands would not have gone unnoticed by Leibniz, they conclude that during the middle years at least he must have had no settled view of the matter. Thus Garber, who once urged a realist interpretation of the middle years ontology, has recently suggested that the Leibniz of this period may be no more a realist than an idealist. ${ }^{3}$ Instead, he maintains that during this period of his development Leibniz just didn't take a position concerning the status of the corporeal world. Yet another possibility has been proposed by Glenn Hartz, who sees Leibniz as what he calls a 'theory pluralist'. The theory pluralist's goal is not to endorse a single theory, but rather to explore and make the case for competing theories, much like an attorney who has been asked to serve as both prosecutor and defender, but who does not necessarily believe what she asserts in these capacities. As a theory pluralist, then, Leibniz should not be forced into either the realist or the idealist mold. At times he champions realism, and at times idealism, but never does he come to embrace one of these theories to the exclusion of the other.

Advocates of such incompatibilist approaches have tended to focus on Leibniz's claims about the status of bodies. But these approaches

${ }^{3}$ Daniel Garber, 'Leibniz and Idealism', in Donald Rutherford and J.A. Cover (eds.), Leibniz: Nature and Freedom (New York: Oxford University Press, 2005), 95-I07. Note that in his more recent book (Leibniz), Garber appears to return to the view that the Leibniz of the middle years was a committed realist about body.

${ }^{4}$ Glenn Hartz, Leibniz's Final System: Monads, Matter and Animals (New York: Routledge, 2007). 
seem equally applicable to his claims about another aspect of the corporeal world: namely, the motions of bodies. As we shall see below, his remarks on the nature of motion seem to exhibit the same ambivalent character as his remarks on bodies. There are many texts from the middle years in which Leibniz characterizes motion as a phenomenon or appearance. There are many others in which he appears to grant the existence of 'real motion', that is, motion understood as a real rather than apparent feature of the world. So in some texts he comes across as a realist, and in others a phenomenalist. To make matters worse, Leibniz appears to contradict himself on various other points about motion. For example, in those contexts in which he adopts a phenomenalist perspective, he also tends to define motion as a mere change in one body's position relative to that of another; but in those contexts in which he adopts a realist cast of mind he seems to conceive motion as more than just such a change: namely, as a change of position together with its cause, that is, a force. Further, in the former contexts he often claims that motion is relative, and that we can never discover which bodies are the true subjects of motion, whereas in the latter contexts he seems to maintain that because motion involves force, it is absolute, and its true subjects can be discovered. The tensions in Leibniz's discussions of motion therefore appear to run rather deep. Though some commentators have read the Leibniz of the I680s and I69os as an idealist about motion, and others as a realist, it is tempting to conclude instead that his claims are simply incompatible, and that for one reason or another he failed to commit to a single, consistent view of motion during this period of his development.

I believe it would be a mistake to yield to this temptation. Though on their face Leibniz's claims do seem to bristle with tensions, I want to argue that these tensions are only apparent, and that they vanish once we become sensitive to certain nuances in his account which have tended to go unnoticed. My primary aim in what follows will be to recover these nuances and show how they allow us to reconcile his apparently contradictory claims about motion. That will be the task of $\S 3$. In the meantime I want to set the stage by presenting the textual evidence for ascribing these apparently inconsistent doctrines about motion to Leibniz (§I), and casting doubt on one strategy for resolving these tensions proposed recently by Samuel Levey (\$2). In $\S_{4}$, I conclude by considering whether the view of motion I impute to 
the Leibniz of the middle years ranks as a kind of realism or rather as some kind of phenomenalism or idealism. In addition to contributing to the larger project of defending a compatibilist reading of Leibniz's ontology in the middle years, then, a secondary aim of the paper will be to contribute to the debate among compatibilists concerning exactly what kind of ontological status he grants to the corporeal world during this crucial phase of his development.

\section{TWO APPROACHES TO MOTION}

For reasons that will become clear below, it will be helpful to think of Leibniz's apparently inconsistent doctrines about motion as forming two coherent but mutually exclusive approaches. For lack of better names, I will call one of them the phenomenalist approach and the other the realist approach. Let us consider these in turn.

\subsection{The Phenomenalist Approach}

In the writings of the middle years Leibniz frequently assimilates what he calls the 'geometrical' or 'intelligible' qualities of bodies, among which he includes motions, to 'sensible' qualities such as color and sound, which he relegates to the realm of phenomena. At the same time, he contrasts all these qualities with force, which he considers real. Here is a typical example, from the essay De modo distinguendi phaenomena realia ab imaginariis: 'Concerning bodies I can demonstrate that not only light, heat, color, and similar qualities are apparent, but also motion, shape, and extension. And if anything is real, it is only active and passive force, to the extent that the substance of a body consists in this (as matter and form)' (A VI. iv. I504/L 365). ${ }^{5}$ In passages such as this, Leibniz aims to distinguish himself from the run of early modern philosophers, and particularly the Cartesians, who grant that sensible qualities are apparent but insist that the intelligible qualities of bodies

\footnotetext{
${ }^{5}$ On the dating of this essay see A VI. iv. I498; for other such texts, all composed between I683 and I695, see Mira de natura substantiae corporeae, A VI. iv. I465/LOC 263; DM I2; Leibniz to Arnauld, 9 October I687, GP ii. II9/L 343; Leibniz to Foucher, n.d., GP i. 392/ WF 55; Specimen inventorum de admirandis naturae generalis arcanis, A VI. iv. I623/LOC 315 ; Specimen dynamicum, GM vi. 248/AG I3I.
} 
are real. As he sees it, these philosophers have drawn the line between the real and the apparent at the wrong place. Though shape, size, and motion may be more real or less imaginary than color and sound, they still fall short of being real, and if anything in the corporeal world is real, it is force. ${ }^{6}$

Why does Leibniz regard motion as only an appearance? The beginning of an answer can be found in this passage from the essay Mira de natura substantiae corporeae, probably composed in 1683 or shortly thereafter:

[J] ust as color and sound are phenomena, rather than true attributes of things containing a certain absolute nature without relation to us, so too are extension and motion. For it cannot really be said just which subject the motion is in. Consequently, nothing in motion is real besides the force and power vested in things (A VI. iv. I465/LOC 263) ${ }^{7}$

Once again Leibniz claims that motion, like color and sound, is a phenomenon and not a true attribute of things with an absolute nature. But here he goes further, adding that motion's status as a phenomenon follows from our inability to discover which of the bodies changing positions relative to one another are really moving. In other words, Leibniz draws a metaphysical conclusion about the nature of motion from what he takes to be a fact about the epistemology of motion. Why, though, does he accept this epistemic thesis? And why does he think it implies that motion is only a phenomenon? For the answers to these questions, we must look elsewhere.

Leibniz gives a fuller presentation of his argument for the phenomenality of motion in this undated text most likely composed in the early i68os:

That matter and motion are only phenomena, or contain in themselves something imaginary, can be understood from the fact that different and contradictory hypotheses can be made about them, all of which nevertheless satisfy the phenomena perfectly, so that no reason can be devised for determining which of them should be preferred. In real things, on the other hand, every truth can be accurately discovered and demonstrated. Thus concerning

\footnotetext{
${ }^{6}$ See $D M$ I2. Cf. Leibniz to Arnauld, 9 October I687, GP ii. II9/L 343; Leibniz to Foucher, n.d., GP i. 392/WF 55.

${ }^{7}$ According to the Akademie editors, Leibniz composed this essay on an invoice dated 29 March I683; see A VI. iv. I465.
} 
motion I have shown elsewhere that it is not possible to determine which subject it is in. (A VI. iv. I463/LOC 257)

Here again Leibniz argues that motion is a phenomenon; and in doing so, as before, he appeals to the point that we cannot tell which bodies are the true subjects of motion. But here he supplies two additional details. First, he reveals his reason for accepting this epistemic thesis. As he has it, we cannot discern which bodies are truly moving because in any situation we are bound to encounter a multitude of mutually exclusive but empirically adequate hypotheses about the motions of bodies. Since these hypotheses all satisfy the phenomena perfectly, Leibniz says, 'no reason can be devised for determining which of them should be preferred'. Hence, these hypotheses are radically underdetermined by the data of experience, making it impossible for us to discover the true subjects of motion. Second, in this version of the argument Leibniz supplies a critical premise which he apparently suppressed in the previous text: namely, the principle that every truth about a real thing can be accurately discovered and demonstrated. According to Leibniz, this principle, together with the aforementioned epistemic point, entails that motion is unreal; for if we cannot discover or demonstrate which bodies are motion's true subjects, then we cannot discover and demonstrate every truth about motion. But since that which is not real is phenomenal, it also follows that motion is a phenomenon.

Leibniz fills in more of the picture in an untitled essay from the late I680s in which he addresses the dispute between the Copernicans and the geocentrists. The essay opens with these words:

Having already proved through geometrical demonstrations the equivalence of all hypotheses with respect to the motions of any bodies whatsoever that are moved only by collision with other bodies, it follows that not even an angel could discern in mathematical rigor which of the many bodies of that sort is at rest, and which is the center of motion for the others. And whether the bodies are moving freely or colliding with one another, it is a wondrous law of nature that no eye, wherever in matter it might be placed, has a sure criterion for discerning from the phenomena where there is motion, how much there is, or of what kind it is, or even whether God moves everything around the self or the self around everything. And in sum I will say that since space without matter is an imaginary thing, motion is in mathematical rigor nothing but a change in the 
positions of bodies among themselves, and so is not something absolute, but consists in a relation. (C 590/AG 9I $)^{8}$

When Leibniz speaks here of the 'equivalence of hypotheses' concerning motion, he does not mean that the hypotheses are equivalent in content, since after all they do assign motions to bodies in different ways. His point is that they are equivalent with respect to their observational consequences. That is, they are all perfectly consistent with what we experience, and that is why we cannot tell 'from the phenomena' which bodies are moving. As in the previous text, then, Leibniz is making the point that because our hypotheses about motion are underdetermined by the empirical evidence, we cannot know which bodies are the true subjects of motion. What makes this passage particularly interesting is that after making this point, Leibniz relates it to two other doctrines about motion. He claims that motion is in mathematical rigor just a change in the relative position of bodies. Then he asserts that because motion is just such a change, it is not absolute but something relational. Though he doesn't explain exactly how these doctrines relate to the equivalence of hypotheses or to our inability to discover the true subjects of motion, what is clear, and what is most important for our purposes, is that he does see them as related. ${ }^{9}$

Another passage in which Leibniz connects the relativity of motion with the epistemological point that we cannot discern motion's true subjects can be found in the Specimen dynamicum of I695; it occurs within the context of a discussion of the laws of motion and comes just a few lines before he remarks that motion, unlike force, belongs among phenomena and relations:

[W] must hold that, if some number of bodies are in motion, it is not possible to infer from the phenomena which of them is in absolute, determinate motion or rest, since we can attribute rest to any one of them and the same phenomena will result. It therefore follows ... that the equivalence of hypotheses is not changed even by the collision of bodies with one another, and that laws of motion must be assigned in such a way that the relative nature of motion is preserved, so that we cannot tell, on the basis of the phenomena resulting from a collision, where there was rest or determinate absolute motion before the collision. (GM vi. 247/AG I3I)

\footnotetext{
${ }^{8}$ Cf. Dynamica, GM vi. 507-8.

${ }^{9}$ For more on how these doctrines relate to one another, see $\$ 3.3$ below.
} 
Here we find Leibniz insisting that if the laws of motion made it possible for us to infer from the phenomena to what degree a body was moving prior to colliding with some other body, then those laws would conflict with motion's 'relative nature'. Why this would happen he doesn't explain; but his underlying thought is evidently that motion's relative nature, whatever that amounts to exactly, implies the existence of equivalent hypotheses concerning motion, which in turn implies that we cannot discover from the phenomena which bodies are truly moving. I will have more to say below about the connection between the relativity of motion and the equivalence of hypotheses (see \$3.3), but for now what matters is merely that in Leibniz's mind they are connected.

Judging from the texts considered thus far, then, Leibniz appears to have accepted each of the following doctrines:

(PI) Motion is nothing but a change of position relative to other bodies.

(P2) Motion is not absolute but something relative.

$\left(\mathrm{P}_{3}\right)$ When bodies change position relative to one another, an equivalence of hypotheses prevents us from determining which of the bodies are truly in motion or to what degree.

$\left(\mathrm{P}_{4}\right)$ Motion is not real but only an appearance or phenomenon.

Further, he appears to have viewed these doctrines as forming a single approach to motion, insofar as he takes $\mathrm{P}_{\mathrm{I}}$ and $\mathrm{P}_{2}$ to imply, respectively, $\mathrm{P}_{2}$ and $\mathrm{P}_{3}$, and $\mathrm{P}_{3}$, together with the premise that all truths about real things can be accurately discovered and demonstrated, to imply $\mathrm{P}_{4}$.

\subsection{The Realist Approach}

The problem is that in other texts from the same period we find Leibniz urging what appears to be a very different approach to motion. Consider to begin with the following passage from his Animadversiones in partem generalem Principiorum Cartesianorum, which he circulated in I692 with a view toward publication:

If motion is nothing other than change of contact or immediate vicinity, it follows that we can never define which thing is moved. For just as in astronomy the same phenomena are satisfied by different hypotheses, so it will always be 
possible to attribute real motion [motum realem] to one or the other of the things that change vicinity or place between themselves.... Hence if there is nothing more in motion than a change of this sort, it follows that there must be no reason in nature to ascribe motion to one thing rather than to others. The consequence of this will be that there is no real motion [motum realem]. In order to say that something is moving, therefore, we will require not only that it change place with respect to other things but also that there be within itself a cause of change, a force, an action. (GP iv. 369/L 393)

It's true that in this passage Leibniz does not explicitly deny any aspect of the phenomenalist approach. He argues only for this conditional: if motion is a mere change of relative position, then we cannot discover its true subjects and thus there can be no real motion. Assuming that in this context 'real' contrasts with 'apparent', we may express this conditional in terms of the phenomenalist doctrines introduced above as follows: $\mathrm{P}_{1} \rightarrow\left(\mathrm{P}_{3} \& \mathrm{P}_{4}\right)$. Notice, however, that in the final sentence of the passage Leibniz indicates that real motion requires that a body not only change place but also contain a cause of that change (i.e. a force). From this we may infer that on his view, if a body does contain such a force, then $\mathrm{P}_{1}$ will be false, and the inference to $\mathrm{P}_{3}$ and $\mathrm{P}_{4}$ will be blocked. ${ }^{10}$ This is significant because throughout the middle years Leibniz frequently claims that such forces are present in bodies. As he says in the Specimen inventorum de admirandis naturae generalis arcanis, '[M]otive force, or the power of acting, is something real and can be discerned in bodies. Thus the essence of body is located not in extension and its modifications ... but solely in the force of acting and resisting' (A VI. iv. I623/LOC 3I5-I7). ${ }^{11}$ Read against the background of the Animadversiones passage, texts such as this suggest that Leibniz means to reject $\mathrm{PI}_{\mathrm{I}}$, in the process at least opening the door to the possibility of real motion. ${ }^{12}$

10 Though strictly speaking Leibniz says only that force is necessary for real motion, he appears to consider it sufficient for real motion as well.

11 On the dating of this piece, see A VI. iv. I6I5. For other texts in which Leibniz affirms the presence of forces in bodies (or corporeal substances), see De modo distinguendi phaenomena realia ab imaginariis, A VI. iv. I504/L 365; DM I8; Specimen inventorum, A VI. iv. I630; Motum non esse absolutum quiddam, A VI. iv. I638; Leibniz to Arnauld, 30 April I687, GP ii. 98/AG 86-7; Leibniz to Huygens, I2/22 June I694, GM ii. I84-5/AG 308; Specimen dynamicum, GM vi. $247 / \mathrm{AG} \mathrm{I}_{3} \mathrm{O}$.

12 Cf. Paul Lodge, 'Leibniz on Relativity and the Motion of Bodies' ['Relativity'], Philosophical Topics, 3I (2003), 277-308. According to Lodge, the conditional argument sketched in the Animadversiones represents 'the culmination of a strand of thought that 
In still other texts from the middle years Leibniz appears to reject $\mathrm{P}_{3}$, the doctrine that an equivalence of hypotheses prevents us from discovering which bodies are truly moving. In some of these, he identifies force as the key to discovering which hypothesis about motion is correct. In the Discours de métaphysique, for instance, he contends that though changes of place are 'not entirely real' and afford us no grounds for judging which bodies are truly moving, 'the force or proximate cause of these changes is something more real, and there is sufficient basis to attribute it to one body more than to another'. He then adds: 'Also, it is only in this way that we can know to which body the motion belongs' ( $D M$ I8). The equivalence of hypotheses may therefore prevent us from discerning from the changes of place themselves which ones are real motions; but according to this passage, that equivalence does not prevent us from discovering which bodies contain forces, and in this roundabout way, to discover which bodies are really moving. Similarly, in a letter to Arnauld from the following year Leibniz writes that 'motion, insofar as it is only a modification of extension and change of location, involves something imaginary, so that we cannot determine to which of the changing subjects it belongs, unless we have recourse to the force which is the cause of motion and which is in the corporeal substance' (GP ii. 98/AG 86-7). Again the thought appears to be that our ability to discover which bodies contain forces affords us an indirect means of determining to which bodies to ascribe the real motions, the underlying principle being that where there's force, there's real motion. ${ }^{13}$

dates back to the late I670s' (283) and as such constitutes 'the definitive expression of Leibniz's intention' (278). Such a position suggests that Leibniz's intent, even in the 'phenomenalist' texts discussed above, may never have been to affirm $\mathrm{PI}_{1}-\mathrm{P}_{4}$ but only to argue that acceptance of $\mathrm{P}_{1}$ engenders a commitment to $\mathrm{P}_{2}-\mathrm{P}_{4}$. And if that were so, we could read him as consistently rejecting those doctrines, thereby dissolving the apparent tension between the phenomenalist and realist strands in his thought. To read him this way, however, would be unacceptable. As we have seen in $\S_{\text {I.I. }}$, there are many texts from the middle years in which Leibniz unequivocally affirms $\mathrm{P}_{\mathrm{I}}-\mathrm{P}_{4}$, and it would be quite a stretch to read these texts as having a conditional character akin to that of the Animadversiones argument. Furthermore, Lodge's selection of the Animadversiones text as the definitive expression of Leibniz's intention seems arbitrary, since other, unmistakably phenomenalistic texts (e.g. those from the aforementioned essay on Copernicanism and from the Specimen dynamicum) have an equal claim to being definitive.

${ }^{13}$ Leibniz does not, in these texts, actually affirm that we can discover the real motions of bodies; what he says is that such discoveries can be made only by having recourse to force. 
In other texts in which Leibniz rejects $\mathrm{P}_{3}$, he makes no mention of force. Instead he maintains that we can discover which bodies are really moving simply by assessing which hypothesis about motion has the greatest simplicity or intelligibility. As he explains in a I694 letter to Huygens, 'I hold, of course, that all hypotheses are equivalent, and when I assign certain motions to bodies, I do not and cannot have any reason other than the simplicity of the hypothesis, since I believe that one can hold the simplest hypothesis (everything considered) as the true one' (GM ii. I99/AG 308; cf. A VI. iv. I620/LOC 3II). In other writings he identifies intelligibility rather than simplicity as the appropriate standard. For instance, in the aforementioned essay on Copernicanism he writes:

Since people do nevertheless assign motion and rest to bodies, even to those they believe to be moved neither by an intelligence nor an impulse, we must look into the sense in which they do this so that we do not judge that they have spoken falsely. And here we reply that one should choose that hypothesis which is more intelligible, and that the truth of a hypothesis is nothing other than its intelligibility. (C 590-I/AG 9I; cf. GM vi. 508)

Some six years later, he would reiterate this point in his Système nouveau de la nature et de la communication des substances: 'It is reasonable to attribute to bodies true motions [veritables mouvemens] according to the hypothesis which gives the most intelligible reason for the phenomena' (GP iv. 487/AG I45). Though Leibniz believes the hypotheses about motion are equivalent, then, he evidently does not consider them equivalent in every respect, since they may differ with respect to simplicity or intelligibility. And this difference, he thinks, enables us to say which bodies are truly moving; for we may reasonably suppose that the simplest or most intelligible hypothesis is the true one. Thus in astronomy, for example, we may justifiably conclude that the Earth is really in motion around the Sun rather than the other way around, because of all the hypotheses consistent with the phenomena, the Copernican one is 'the most intelligible theory and the only one capable of an explanation sufficient for a person of sound reason' (C 59I-2/AG 92). 
For my purposes it is of little importance that Leibniz appears to vacillate concerning the grounds of our ability to discover the true subjects of motion; what matters is only that he believes we can make such discoveries. ${ }^{14}$ It should be noted, however, that the apparently conflicting proposals - one focusing on force, another on simplicity, and yet another on intelligibility-need not be viewed as incompatible. In the first place, when Leibniz speaks of the simplest hypothesis, he clearly does not mean the absolutely simplest one, which would perhaps be that every body is at rest. What he means is the simplest of the hypotheses that satisfy the phenomena; and it may well be that the simplest such hypothesis, the one that provides the simplest explanation of the phenomena, will also be the most intelligible one. Further, Leibniz's idea that the simplest or most intelligible hypothesis reveals which bodies are truly in motion may actually go hand-in-hand with his suggestion that we can discover the true subjects of motion only by having recourse to force, for, as I shall argue in \$3.I, intelligibility can serve as a reliable guide to the truth of a hypothesis only if (and because) it reliably tracks the distribution of forces in nature. It may therefore be that these apparently competing proposals actually represent different ways of expressing one and the same proposal.

Here it is necessary to pause to consider an objection. In suggesting that the most intelligible hypothesis about motion may be considered the true one, Leibniz appears to contradict himself, since he also claims that the equivalence of all such hypotheses prevents us from identifying a correct one (i.e. $\mathrm{P}_{3}$ ). The threat of this tension has moved some scholars to urge an alternative understanding of the significance of Leibniz's intelligibility criterion. As they have it, his point is not that the most intelligible hypothesis is true, but only that it is the most convenient, and thus that we are justified in taking it to be truespeaking and acting as if it were true- on purely pragmatic grounds, despite the absence of any reason for actually believing it to be true. ${ }^{15}$

\footnotetext{
14 In addition to the ones mentioned here, Leibniz proposes still other ways in which we may discern the real motions of bodies. For discussion of these proposals, see Lodge, 'Relativity', 290-4.

${ }^{15}$ See G. H. R. Parkinson, 'Science and Metaphysics in the Leibniz-Newton Controversy', in K. Müller and W. Totok (eds.), Akten des Internationalen Leibniz-Kongresses Hannover (1966), Bd. 2, Mathematik-Naturwissenschaften (Studia Leibnitiana Supplementa 2) (Wiesbaden: Franz Steiner, 1969), 79-II2, esp. I07-8; Richard Arthur, 'Space and Relativity in Newton
} 
Now if this were correct, then Leibniz's belief that we should privilege the most intelligible hypothesis would in no way conflict with his endorsement of $\mathrm{P}_{3}$, contrary to what I have suggested. However, the evidence actually weighs rather heavily against such an instrumentalist reading. In the first place, notice that this reading does nothing to help ease the tension between $\mathrm{P}_{3}$ and those passages in which Leibniz indicates that we can discover the true subjects of motion (or equivalently, the correct hypotheses of motion) by having recourse to force; at most it provides only a partial solution. Second, Leibniz himself never gives any clear indication that he means for his intelligibility criterion to be interpreted instrumentally. ${ }^{16}$ If anything, his language suggests just the opposite. For instance, he touts the superior intelligibility of his system of pre-established harmony as evidence of its truth, and in support of this he says:

I have always observed in astronomy and physics that the most intelligible hypotheses prove true in the end: for example, that of the motion of the earth to save the appearances of the stars, and that of the weight of the air to explain air pumps and other attractions that had formerly been attributed to the abhorrence of a vacuum. (GP iii. 353)

Clearly the point here is not that the most intelligible hypothesis is merely convenient, but that it's actually true, and this no less in physics than in metaphysics. Third, given that Leibniz considers this world the

and Leibniz', British fournal for the Philosophy of Science, 45 (I994), 2 I9-40, esp. 23I-2. Cf. Anja Jauernig, 'Leibniz on Motion and the Equivalence of Hypotheses' ['Leibniz on Motion'], Leibniz Review, I8 (2008), I-40, at 8-9, I9-20.

${ }^{16}$ It is true that in the Specimen dynamicum, after having emphasized that the relative nature of motion prevents us from discerning from the phenomena which bodies are the true subjects of motion, Leibniz issues the following qualification: 'Meanwhile we speak as the situation requires, in accordance with the more appropriate and simpler explanation of the phenomena, just as in spherical astronomy [Sphaericis] we use the motion of the primum mobile, and in planetary theory we ought to use the Copernican hypothesis' (GM vi. 248/AG I3I). We might be tempted to take this as evidence of the sort of instrumentalist reading under consideration. To do so, however, would be a mistake. The principle Leibniz endorses in this passage is that we ought always to adopt that perspective which is the most appropriate relative to our aim. And he specifies that when our aim is that of articulating a theory of the motions of the planets, we ought, in accordance with this principle, to adopt the Copernican perspective. But what he doesn't specify-crucially—is whether the adoption of this perspective would be appropriate merely because of its utility, or because of all the hypotheses consistent with the phenomena, it's the one that stands the best chance of being true. This text is therefore neutral as between the instrumentalist reading and the one I am urging here. 
most intelligible possible world, ${ }^{17}$ it stands to reason that on his view the most intelligible hypothesis, all things considered, is actually true. Finally, as we shall soon see (cf. §3.I), the instrumentalist reading turns out to be unmotivated, since it's possible to find in Leibniz's writings the ingredients for an alternative approach to this problem which is not only more in keeping with what he actually says, but which promises to effect a more thoroughgoing resolution of the seemingly conflicting strands in his thought. We may therefore safely set aside this instrumentalist suggestion.

Let us return to our previous train of thought. I have been arguing that in claiming that we can discover which changes of position are the real motions, Leibniz appears to be rejecting $\mathrm{P}_{3} \cdot{ }^{18}$ But now I want to emphasize that he appears to be rejecting more than just that. In the first place, if only some changes of position count as real motions, then evidently the other changes of position aren't really motions; but in that case motion must be more than just such a change, contra PI. Further, Leibniz seems to commit himself to the view that motion is absolute rather than relative. For in claiming that forces are absolute, he suggests that they belong to bodies absolutely and not just relative to

17 See, e.g. GP vi. 236/H 201.

18 An anonymous referee has suggested that I may be overlooking an important change in Leibniz's view. According to this referee, Leibniz was originally concerned to deny only that an experiment could reveal whether a body is in uniform rectilinear motion, but then in the late I680s, in response to Newton's bucket experiment, began to make the stronger claim that no experiment could reveal whether a body is undergoing any sort of absolute motion at all (uniform, accelerated, rectilinear, curvilinear, etc.). This stronger claim, the referee suggests, implies that we do not even have the means to discover forces, and that by the late I680s Leibniz had given up his earlier belief that we can discover the true motions of bodies by having recourse to force. I respond that even if Leibniz did come to accept this stronger form of relativity only in the late I680s, which is far from clearly the case, it doesn't follow that he gave up the idea that we can discover the absolute motions of bodies by having recourse to force. Leibniz's claim, both before and after the late I680s, is that we cannot discern the true motions of bodies from the phenomena, and this implies that the phenomena do not allow us to discern the forces in bodies. But nowhere does he say that our knowledge is limited to what can be discovered from the phenomena. It may well be that on his view, limiting ourselves to the phenomena is just what considering motion in itself amounts to, whereas considering motion with respect to cause involves going beyond the phenomena by, say, appealing to considerations of intelligibility. (Cf. Leibniz's claim at A VI. iv. I623/ $L_{3}$ I6-I7 that we perceive forces not by the imagination but by the intellect.) Understood in this way, the stronger relativity thesis is perfectly consistent with the claim, which Leibniz sometimes makes even in the I69os and beyond (see A II. ii. 32I; GP iv. 400/AG 256), that we can discover the true subjects of motion by having recourse to force. Cf. note 3I below. 
a hypothesis or frame of reference. Yet he also holds that a body's change of position counts as a real motion just in case it contains a force suitable to be the cause of that change. Thus it would appear that on his view not just forces but also motions belong to bodies absolutely, contra $\mathrm{P} 2$. Finally, insofar as Leibniz believes that some motions are real, he evidently means to reject $\mathrm{P}_{4}$, the doctrine that (all) motion is just an appearance.

What the texts considered in this section suggest, therefore, is nothing less than a wholesale rejection of the phenomenalist approach to motion, and the acceptance in its place of what may be characterized as a kind of realist approach to motion. ${ }^{19}$ In opposition to $\mathrm{P}_{\mathrm{I}}-\mathrm{P}_{4}$, that is, Leibniz appears to accept each of the following doctrines:

(RI) Motion consists in a change of position relative to other bodies together with a cause of this change, that is, a force.

(R2) Motion, like force, is something absolute.

( $\left.\mathrm{R}_{3}\right)$ Despite the equivalence of hypotheses about motion, we can discover which bodies are truly in motion and to what degree.

(R4) Some motions (i.e. those grounded in force) are not appearances or phenomena, but real, perception-independent features of the world.

So in the writings of the middle years we find evidence of not one but two approaches to motion. These approaches are clearly incompatible, and so we cannot simply combine them to form a single coherent approach. Nor will it do to suppose that Leibniz just changed his mind about motion at some point during this period, since evidence of both approaches can be found in writings from throughout the period, both early and late. Unless we can find a way to resolve these apparent tensions without doing violence to his words, then, it seems we must join the incompatibilists in concluding that Leibniz had no settled view of motion during this period.

19 Texts such as these have led Samuel Levey to read Leibniz as a 'nuanced realist' about motion. See Levey, 'Precise Shapes', 9г. Even R. C. Sleigh, Jr., himself no fan of realist interpretations of Leibniz, admits that when it comes to motion 'there is much to be said in favor of the realistic claim' (Leibniz and Arnauld, II2). 


\section{LEVEY'S DOUBLE-ASPECT READING}

One strategy for dealing with these apparent tensions would be to follow Samuel Levey in holding that Leibniz has a 'two-sided' view of motion, with motion as it appears on the one side, and motion as it is in itself on the other. 'As it appears to us', Levey explains, 'motion has to be understood to involve something imaginary; as it is behind the appearances, relational change of place is caused by absolute changes that are intrinsic to the bodies themselves and constitute 'true motion'. And the account reductively identifies that true motion with force'. ${ }^{20}$ Levey thus understands Leibniz to be propounding what amounts to a double-aspect theory of motion. Considered as it appears, motion is or at least involves something imaginary. As it is in itself, however, motion is something behind the appearances and therefore must be real. Further, whereas motion as it appears is a 'relational change of place', motions in themselves are 'absolute changes' that are 'reductively identified' with force. Motion in itself is therefore really just force, and as such is real, absolute, and intrinsic to bodies. But we perceive motion only as it appears, and this appearance is something imaginary, relative, and extrinsic to bodies.

The relevance of this reading to the problems at issue here should be obvious. If motion as it appears is apparent, relative, and nothing more than a change of position, whereas motion in itself is real, absolute, and something more than just a change of position (i.e. a force), then we can understand Leibniz as coherently accepting much of both the phenomenalist and realist approaches. For we can read at least three of the phenomenalist doctrines- $\mathrm{P}_{1}, \mathrm{P}_{2}$, and $\mathrm{P}_{4}$-as claims about motion as it appears, while reading $\mathrm{R}_{1}, \mathrm{R}_{2}$, and $\mathrm{R}_{4}$ as claims about motion in itself. In that case none of these opposing doctrines would conflict, since none of them would be true of motion considered under any one aspect.

What about the tension between $\mathrm{P}_{3}$ and $\mathrm{R}_{3}$ ? Here the situation is more complicated. Note that $\mathrm{P}_{3}$ amounts to the claim that we cannot discover to which bodies we ought to assign real motion, that is, motion in itself; so there seems to be little prospect of construing it

20 Levey, 'Precise Shapes', 73. 
as a claim about motion as it appears. For this reason, perhaps, Levey takes a different approach to this tension. Though he admits that 'Leibniz's own account of motion postulates an intrinsic property of individual bodies that institutes an absolute distinction between those that move and those that are at rest', he also says of this distinction that 'only God might be able to draw it correctly'. ${ }^{21}$ This is because on Leibniz's view, 'The change in a body in virtue of which change of place occurs is not something we can distinguish, and so our naïve (imagined) assignment of absolute motion to individual bodies is in itself unfounded and can at best be only accidentally correlated with the underlying facts'. ${ }^{22}$ Evidently, then, Levey would propose to resolve the apparent tension between $\mathrm{P}_{3}$ and $\mathrm{R}_{3}$ by simply denying that $\mathrm{R}_{3}$ is a part of Leibniz's considered view of motion. As we saw in $\S$ I.2 above, however, there are many texts in which Leibniz appears to endorse R3: for example, texts in which he claims that we can ascertain which bodies are truly in motion by having recourse to force or by identifying the most intelligible hypothesis. Levey himself does not address these texts, and it is unclear how his view might be reconciled with them. Thus his reading, as it stands, does not really come to grips with this problem. Still, his interpretation promises to go a long way toward easing the tension between the realist and phenomenalist approaches, and that is significant in itself.

There are nonetheless good reasons for doubting whether Levey's interpretation accurately captures Leibniz's thought. In the first place, Leibniz gives few indications that he wants to restrict any of his realist or phenomenalist doctrines to motion considered only under a certain aspect. That which is said to be relative and phenomenal, for example, is not motion as it appears but just motion (i.e. motion simpliciter). Likewise, it is always motion (simpliciter), not motion in itself, which Leibniz characterizes as real. There is, moreover, little reason to think that Leibniz himself ever thought in terms of a distinction between motion in itself and motion as it appears. He certainly does speak of 'motion in itself'. In the I677 piece Quod motus sit ens respectivum, for example, he remarks that 'when we consider motion not formally in itself, but with respect to cause, it can be attributed to the body of that

$\begin{array}{ll}21 & \text { Ibid., 72, } 88 . \\ 22 & \text { Ibid., 72. }\end{array}$ 
thing through contact with which change is brought about' (A VI. iv. I970/LOC 229). And he writes to Arnauld that 'motion in itself, abstracted from its cause, is always something relative' (GP ii. 57/L 337). But we must be careful not to confuse the distinction Leibniz has in mind in these texts with the distinction Levey imputes to him. In these texts, and others like them, Leibniz is not contrasting motion in itself with motion as it appears; rather, he's contrasting motion in itself with motion considered with respect to cause. To consider motion in itself, he thinks, is to consider motion and nothing else. But to consider motion with respect to cause is to consider not just the motion itself but also its cause, that is, a force. When Leibniz speaks of motion in itself, therefore, he means to exclude force from consideration, whereas Levey's suggestion was that motion in itself really just is force. The concept of motion in itself that Levey imputes to Leibniz is thus quite different from what Leibniz himself has in mind when he speaks of motion in itself.

To be sure, Leibniz does characterize force as the reality 'in' motion. As he puts it in a typical passage, 'there is nothing real in motion but a momentary something which must consist in a force striving toward change' (GM vi. 235/AG II 8). ${ }^{23}$ Such remarks are significant because they might be thought to imply that motion in itself is really just force, and thus that when Leibniz contrasts force with motion, as he frequently does, he intends to be contrasting what motion really is (i.e. force) with what it appears to be. The inference from force being the reality 'in' motion to force being what motion is in itself, however, is dubious. It may well be, as I believe, that Leibniz understands the term 'motion' to refer to something the essence of which is to be an appearance. In that case, however, the distinction between motion in itself and motion as it appears would collapse: motion in itself would be an appearance, and therefore something distinct from force. Yet it would still make sense for him to speak of force as the reality 'in' (or 'behind') this appearance. So the mere fact that force is 'in' motion does not entail that motion is really just force. A further problem is that

23 See also Mira de natura substantiae corporeae, A VI. iv. I465/LOC 263; Leibniz to Arnauld, 9 October 1687, GP ii. II5/L 34I; Animadversiones, GP iv. 369/L 393; Eclaircissement des difficultés que Monsieur Bayle a trouvées dans le système nouveau de l'union de l'ame et du corps, GP iv. 523/WF 85. Cf. GP iv. 400/AG 256. 
if this were Leibniz's intention, we would expect him to contrast force with motion-as-it-appears. Yet that isn't the contrast he makes. His contrast is always between force and motion tout court. As he puts it in a typical passage, 'though force is something real and absolute, motion belongs among phenomena and relations, and we must seek truth not

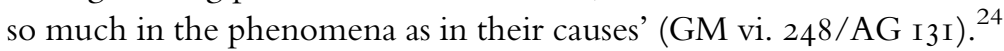
Leibniz's thought therefore seems to be that motion and force differ toto genere, and not, as Levey has it, that motion is in itself really just force. ${ }^{25}$ Force may be the cause of motion, even the reality underlying motion, but it is evidently not that in which motion consists.

Levey's double-aspect approach does not therefore receive much support from the texts. Of course, if some approach along these lines offered the only viable strategy for reconciling the opposing strands in Leibniz's thought, then the absence of any evidence that he himself conceived such a strategy might constitute only a minor drawback, since, after all, absence of evidence is not necessarily evidence of absence. But this is not the only such strategy available to us. In the next section, I sketch an alternative approach to interpreting Leibniz's claims about motion which not only succeeds in resolving the apparent tensions in his thought, but also has the advantage over Levey's reading that it has a solid foundation in the texts. The existence of such an approach will prove to be the strongest reason yet for rejecting Levey's double-aspect reading.

\section{UNDERSTANDING LEIBNIZIAN MOTION}

My proposal will unfold in three stages. In the first, I argue that the distinction introduced above $(\$ 2)$ between two ways of considering motion holds the key to reconciling the most explicit tension in his

24 See also, e.g. De modo distinguendi phaenomena realia ab imaginariis, A VI. iv. I504/L 365; $D M$ I8; Specimen inventorum de admirandis naturae generalis arcanis, A VI. iv. I622-3, I630/LOC 3I5-I7, 333; Leibniz to Arnauld, 23 March I690, GP ii. I37/L 360.

25 Though it falls outside our target period, an untitled essay from I702 contains the following remark in which Leibniz essentially denies that motion reduces to force: 'For all qualities of bodies, that is, except for shapes, all of their real and stable accidents (that is, those which do not exist merely in a transitory way, like motion, but which are understood to exist in the present, even if they make reference to the future) are in the end reduced [revoco] to forces, when analysis is undertaken' (GP iv. 400/AG 256). 
writings about motion: namely, that between $\mathrm{P}_{3}$ and $\mathrm{R}_{3}$. In the second, I argue that a correct understanding of what Leibniz means by 'real motion' (motus realem, véritable mouvement) leads to the conclusion that he neither accepted nor committed himself to either R I or $\mathrm{R}_{4}$. Finally, I resolve the tension between $\mathrm{P}_{2}$ and $\mathrm{R} 2$ by distinguishing two senses in which motion might be thought to be relative and arguing that the sense of relativity operative in $\mathrm{P}_{2}$ differs from that operative in $\mathrm{R} 2$.

\subsection{Two Ways of Considering Motion}

Let us begin by returning to the distinction introduced above between two ways of considering motion. As we have seen, Leibniz believes motion can be considered either in itself, as a mere change of position, or with respect to cause, as a change of position together with the force that causes it. Though little has been made of this distinction by previous commentators, I regard it as critical to reconciling the apparent tension in Leibniz's view concerning our prospects for discovering the true subjects of motion. ${ }^{26}$

In §I.I I quoted a passage from the I677 note Quod motus sit ens respectivum in which Leibniz appears to endorse the phenomenalist doctrines $\mathrm{P}_{2}$ and $\mathrm{P}_{3}$ : 'A remarkable thing: motion is something relative, and we cannot distinguish which of the bodies is moving' (A VI. iv. I970/LOC 229). Just a few lines later, however, he adds a qualification that casts this previous remark in a very different light: 'Note, however, that if we consider motion not formally in itself, but with respect to cause, we can attribute it to the body of that thing which brings about the change through contact' (ibid.). Taken in isolation, the first statement appears to reflect a commitment to the view that we simply cannot tell which bodies are moving. But the second statement reveals that this is not Leibniz's intention. Properly speaking, his view is that we cannot tell which of the bodies is moving if we consider motion only in itself, but that if we go beyond motion itself to consider its cause, we can discover such facts.

${ }^{26}$ For a similar account see Garber, Leibniz, IO6-I5. 
As we move to later writings we find Leibniz making essentially the same point. In the slightly later Definitiones cogitationesque metaphysicae, for example, he claims that "When two bodies approach one another, it can be decided only from the cause of motion, not from the motion itself, which is at rest or in motion, or whether both are moving' (A VI. iv. I400/LOC 249). And in the Discours de métaphysique he has this to say:

[M]otion, if we consider only what it contains precisely and formally, that is, a change of place, is not an entirely real thing, and when several bodies change position among themselves, it is not possible to determine merely from a consideration of these changes to which of them motion or rest should be attributed $[\ldots]$ But the force or proximate cause of these changes is something more real, and there is sufficient basis to attribute it to one body more than to another; also it is only in this way that we can know to which one the motion belongs. ( $D M$ I 8 )

According to this passage, when bodies change position relative to one another we cannot discover which ones are moving 'merely from a consideration of these changes'. But these changes of position-that which motion contains 'precisely and formally' — are just what Leibniz elsewhere identifies as motion in itself. ${ }^{27}$ So his point here, as before, is just that we cannot discover the true subjects of motion from a consideration of motion in itself. ${ }^{28}$ As Leibniz goes on to explain, however, it is within our power to discover which bodies contain forces, and this information allows us to know which bodies are truly moving. So in other words, as long as we consider not just motion but also its cause, we can discover its true subjects.

Another passage in which Leibniz makes this point comes from a letter composed in I690. '[M]otion in itself', he writes, 'is not a real but a relative thing, if it is taken to be a mere change of place. And when several bodies change position among themselves, there is no way to determine the true subject of motion unless we also consider effort, or the cause of motion, which is found in body only to the extent that it participates in real and absolute motion' (A II. ii. 32I). As

\footnotetext{
27 See Leibniz to Arnauld, 28 November/8 December I686 (draft), A II. ii. II2/GP ii. 69-70. Cf. the I689 essay on Copernicanism, C 590/AG 9I; A II. ii. 32 I.

28 Cf. Leibniz to Foucher, 23 May I687, A II. ii. 202/WF 55.
} 
this text makes clear, Leibniz's position is not simply that we cannot discover the true subjects of motion; it is rather that we cannot make such discoveries on the basis of a consideration of motion in itself. If we go beyond the motions themselves to consider their causes, however, then according to Leibniz we can indeed ascertain which bodies are really moving or to what degree. For, evidently, a consideration of the cause of motion (i.e. force) will reveal where those causes are found in nature, and as a body contains force 'only to the extent that it participates in real and absolute motion', this means we can also know to which bodies we should assign real motion.

It is not hard to see how, on Leibniz's view, knowledge of which bodies contain force would lead to knowledge of which bodies are really moving. After all, he believes that the real motions are just those which are caused by, or grounded in, a force within the moving body. What is not so easy to see is how we can come to know which bodies contain forces in the first place. When it comes to my own body, of course, I may be able to sense the presence of a force, as Leibniz acknowledges in an early text. ${ }^{29}$ But in general I cannot sense the presence of forces in bodies. How, then, can I know which bodies contain force? Leibniz himself offers no clear answer to this question, but I want to suggest that this is the point in his account where the criterion of intelligibility comes into play. As we saw in $\S_{\mathrm{I} .2}$, he maintains that we may reasonably take the most intelligible hypothesis to be the true one- - claim which makes sense given his belief that in selecting this world for creation God aimed for maximum intelligibility. But note that the most intelligible hypothesis can be true only if it assigns motions to bodies in accordance with the actual distribution of forces in nature. Considerations of intelligibility thus allow us to discover which bodies contain forces, and, by extension, their real motions. $^{30}$

In light of the texts discussed above and others like them, ${ }^{31} \mathrm{I}$ think we may reasonably conclude that Leibniz accepted neither $\mathrm{P}_{3}$ nor $\mathrm{R}_{3}$,

29 See Specimina de motus causa et de corporum qualitatibus, A VI. iv. 20I9. For discussion of this text, see Lodge, 'Relativity', 277-308, esp. 290-4.

30 For more on this, see my 'Leibniz on Intelligibility and Motion', forthcoming.

31 See Specimina de motus causa et de corporum qualitatibus, A VI. iv. 2017-I8:

$[F]$ or motion I require not only a change of position with respect to others, but also that a cause be in the one to which motion is ascribed; for if we consider only change of position, or 
as such. Though one can certainly produce texts in which he straightforwardly affirms, or appears to affirm, one or the other of these doctrines, we can now see that such texts should be taken with a grain of salt. Properly speaking, his position is that $\mathrm{P}_{3}$ holds true only of motion considered in itself, whereas $\mathrm{R}_{3}$ holds true of motion considered with respect to cause. In other words, he believes that from a consideration of motion itself, we cannot discover which bodies are really moving, but that from a consideration of motion together with its cause (i.e. force), we can make such discoveries. Once we appreciate the significance of this distinction between two ways of considering motion, it becomes clear that this part of Leibniz's account of motion is consistent after all.

\subsection{Motion as a Real Phenomenon}

Next let us consider the tensions resulting from Leibniz's apparent acceptance of the following two pairs of doctrines. The first concerns the definition of motion itself:

(PI) Motion is nothing but a change of position relative to other bodies.

(RI) Motion consists in a change of position relative to other bodies together with a cause of this change, that is, a force.

The second concerns the reality of motion:

$\left(\mathrm{P}_{4}\right)$ Motion is not real but only an appearance or phenomenon.

(R4) Some motions (i.e. those grounded in force) are not appearances or phenomena, but real, perception-independent features of the world.

what is merely mathematical in motion, it is not possible to say to which of the many bodies changing with respect to one another motion should be ascribed.

See also Leibniz to Foucher, 23 May I687, A II. ii. 202/WF 55; Leibniz to Arnauld, 28 November/8 December I686 (draft), A II. ii. II2. Also of significance are texts in which Leibniz claims that we cannot tell 'from the phenomena' which bodies are truly moving (see, e.g. the aforementioned essay on Copernicanism, C 590/AG 9I; Leibniz to Huygens, I2/22 June I694, A II. ii. 8Io/AG 308; Specimen dynamicum, GM vi. 247/AG I3I). It would appear that the phenomena he has in mind in such passages are changes of place, since forces are perceived only by the intellect (Specimen inventorum de admirandis naturae generalis arcanis, A VI. iv. I623/LOC $316-17$ ). His point therefore appears to be that we cannot discover the true subjects of motion from a consideration of motion in itself (i.e. mere changes of position). 
Recall that Leibniz affirms both $\mathrm{P}_{\mathrm{I}}$ and $\mathrm{P}_{4}$ in texts from throughout the middle years. As for the realist doctrines $\mathrm{R}_{\mathrm{I}}$ and $\mathrm{R}_{4}$, he appears to endorse them in the Animadversiones passage in which he (i) argues for the claim that if motion is just a change of position there is no real motion, and (ii) implicitly rejects the consequent of this conditional. For in the first place, if he believes that at least some motions are real, then he presumably accepts $\mathrm{R}_{4}$ rather than $\mathrm{P}_{4}$. Further, not only does his rejection of this consequent imply a rejection of the antecedent (i.e. PI), but he says that in order for a body to undergo real motion, 'we will require not only that it change place with respect to other things but also that there be within itself a cause of change, a force, an action' (GP iv. 369/L 393). So he appears to be suggesting that motion is really a change of position together with a force, as RI has it. Even apart from the Animadversiones passage, though, Leibniz clearly wants to distinguish between those changes of position that rank as real motions and those that don't, as he insists that when bodies change position relative to one another, we can discern which of them are 'really moving' by considering those changes together with their causes. But again, if Leibniz considers some motions real, then it would appear that $\mathrm{R}_{4}$, not $\mathrm{P}_{4}$, captures his view. And if a change of position can fail to be a real motion, then motion, it seems, must be something more than just a change of position, contra $\mathrm{P}_{\mathrm{I}}$; it must be, as $\mathrm{R}_{\mathrm{I}}$ has it, a change of position together with that which elevates such a change to a real motion, namely, a force.

My aim in this section is to resolve these tensions by arguing that Leibniz neither affirms nor commits himself to these realist doctrines, and that he should therefore be interpreted as consistently accepting their phenomenalist alternatives.

Let us begin with the thought that in affirming the existence of real motion, Leibniz commits himself to R4. It is important to realize that this commitment arises only if we suppose that in calling motion real, Leibniz's aim is to indicate that motion is not an appearance or phenomenon. However, this is not the only way, or even the usual way, that Leibniz uses the term 'real' in his writings. He often calls things real not in order to contrast them with appearances, but rather to contrast them with that which is (completely) imaginary. Thus he refers to phenomena which are well-founded, i.e. such things as 
rainbows, bodies, herds, and the like, as 'real' or 'true' phenomena. ${ }^{32}$ In doing so, however, he obviously does not mean to imply that they are real in a sense which is incompatible with their being appearances. His point is instead that they are real rather than imaginary phenomena. Of course they are not absolutely real, since, as Leibniz says, they do 'contain something of the imaginary'. Nevertheless they do derive a measure of reality from the absolutely real things upon which they are founded, and for this reason they qualify as real. In contrast, those phenomena without such a foundation have nothing from which to derive any reality, and since as phenomena they have no reality in themselves, it follows that they are 'completely imaginary'. ${ }^{33}$

Now Leibniz clearly believes that motions are real in this sense which is opposed to 'imaginary'. On at least one occasion, he describes motions as 'real phenomena' (GP ii. 92/AG 82; cf. C 523/AG 34). Further, as he explains in Specimen dynamicum, those motions with a proper foundation in reality are both real and phenomenal:

[F]orce is something absolutely real in substances, even in created substances, while space, time, and motion are to a certain extent beings of reason and are not true or real per se but only to the extent that they involve either the divine attributes (immensity, eternity, the ability to carry out works) or the force in created substances.... [E]ven though force is something real and absolute, motion belongs among phenomena and relations, and we must seek truth not so much in the phenomena as in their causes. (GM vi. 247-8/AG I30-I)

In these two remarks, separated by only a few lines, Leibniz claims both that motion is a phenomenon and that it can be true or real insofar as it involves something absolutely real, namely either force or divine power. Unless he is contradicting himself, then, his point is not that the motions grounded in force are real in a sense which implies that they are not appearances. Rather, his point must be that in virtue of being founded upon absolute realities, these motions, qua

32 See, e.g. Notationes generales, A VI. iv. 555; Divisio terminorum ac enumeratio attributorum, A VI. iv. 559/LOC 265; Specimen inventorum de admirandis naturae generalis arcanis, A VI. iv. I622/LOC 3I5; Principia logico-metaphysica, A VI. iv. I648/AG 34.

33 Cf. Leibniz's statement to Arnauld in a letter dated 30 April 1687 that phenomena 'always have as much reality or substantiality as there is true unity in that which enters into their composition', and that 'phenomena themselves, like the rainbow or a pile of stones, would be completely imaginary if they were not composed of beings with a true unity' (GP ii. $97 / \mathrm{AG} 86)$. 
phenomena, are real rather than imaginary, just as phenomena in general rise above the level of the imaginary by virtue of their being founded upon such realities.

Notice, though, that these motions which Leibniz considers true or real in the sense of non-imaginary, i.e. the motions grounded in force, are precisely the ones he has in mind when he talks about real motion in the Animadversiones or when he suggests that we can discern which changes of position are the real motions. In view of this, I think we may reasonably suppose that whenever Leibniz characterizes a change of position as a real or true motion, his point is not that these changes aren't phenomena, but that they are real or true rather than imaginary phenomena. On this supposition, however, his talk of real motion in no way implies that motion is anything other than a phenomenon, and so he in no way commits himself to $\mathrm{R}_{4}$. The apparent tension in Leibniz's view between $\mathrm{P}_{4}$ and $\mathrm{R}_{4}$ is therefore immediately resolved, and we can simply take him at face value when he says, as he often does, that motion is a phenomenon.

This leaves the problem of whether Leibniz means to define motion as just a change of relative position (per $\mathrm{P}_{\mathrm{I}}$ ) or as such a change together with a force (per Ri). On my view, this problem, like the previous one, arises only because Leibniz appears to accept a doctrine which in fact he does not accept: in this case, RI. Recall that from his perspective many changes of position are not real motions; yet if some such changes are not real motions, the thought goes, it would appear that motion is really more than just such a change. However, this follows only if we suppose that in calling some changes of place real motions, Leibniz means to be distinguishing them from those changes of place which are not motions at all. Only then would it follow that in order to count as a motion, a change of place must be grounded in a force. In contrast, if Leibniz's aim is to distinguish one kind of motion (i.e. the real) from another (i.e. the imaginary), as I am suggesting, then his position in no way implies that a mere change of place is not a motion. It would be perfectly reasonable for him to say that just as a non-real or imaginary phenomenon is still a phenomenon, so also a non-real or imaginary motion is still a motion.

With these points on the table, I am now in a position to offer a reading of the Animadversiones passage discussed above on which it 
engenders no commitment to the realist doctrines R I and R4. Recall that in that text Leibniz argues as follows:

[I] f there is nothing more in motion than this reciprocal change [of contact or immediate vicinity], it follows that there is no reason in nature to ascribe motion to one thing rather than to others. The consequence of this will be that there is no real motion [motum realem]. Thus, in order to say that something is moving, we will require not only that it change its position with respect to other things but also that there be within itself a cause of change, a force, an action. (GP iv. 369/L 393)

I believe the key to understanding this passage is to realize that when Leibniz speaks of the consequence that there is no real motion, he means that there would be no motion that ranks as a real phenomenon; in other words his point is that all motions would be imaginary phenomena. His thought can therefore be paraphrased as follows. If there is nothing more in motion than just a change of position, that is, if there is no force in motion, then we will not be able to say which changes of position are the real or well-founded motions. For it is only the consideration of force that enables us to discover which bodies are really moving. Further, if there are no forces in motion, then there will be no absolute reality from which the motions, as phenomena, may derive their own reality. And so if there is no force in motion, there will be no real motions; instead they will all be imaginary. Hence, Leibniz concludes, 'in order to say that something is moving' - that is, in order to say that some motions are real rather than imaginary phenomena-'we will require not only that it change its position with respect to other things but also that there be within itself a cause of change, a force, an action'. Read in this way, the passage provides no support at all for imputing either $\mathrm{R}_{\mathrm{I}}$ or $\mathrm{R}_{4}$ to Leibniz.

\subsection{The Relativity of Motion}

Our lone remaining problem concerns the relativity of motion. As we have seen, Leibniz frequently insists that motion is not absolute but something relative (i.e. $\mathrm{P}_{2}$ ). Yet he also appears to affirm the existence of real motions, which belong to bodies absolutely and not just relative 
to a frame of reference (i.e. R2). He therefore seems to contradict himself on this point.

Perhaps the most promising attempt to come to grips with this problem has been made recently by Anja Jauernig. ${ }^{34}$ Unlike some commentators, who would try to solve this problem by explaining away, or otherwise ignoring altogether, the evidence for ascribing one or the other of these positions to Leibniz, her position has the advantage that it purports to accommodate all this evidence. On her view Leibniz is a relativist about motion, just as the texts considered in $\S$ I.I show. But he's also an absolutist about motion, as the texts discussed in $\S_{\text {I.2 }}$ suggest. And yet he doesn't contradict himself, because in his system the relative motions and the absolute motions are not, as we might have naïvely assumed, the same motions. According to Jauernig, those motions which are mere changes of position-in her terminology, the 'merely phenomenal' motions - are the ones Leibniz considers relative, whereas those grounded in force-the 'dynamical' motions - are the ones he considers absolute. In other words, when it comes to mere changes of place, such motions can sensibly be ascribed to bodies only relative to a frame of reference, and so they are relative. But the motions grounded in force, the ones Leibniz calls real motions, belong to bodies absolutely and not just relative to a frame. Although motion is both relative and absolute, then, no one motion is both, and so there is no inconsistency.

There is much to be said for this proposal. Most importantly, it provides a simple and elegant reconciliation of $\mathrm{P}_{2}$ and $\mathrm{R} 2$. Simply by restricting the two claims to disjoint classes of motions, Jauernig shows that it is possible for Leibniz to hold both without contradicting himself. Her proposal is also not without textual support. As for the distinction between motion at what she calls the merely phenomenal and dynamical levels, Leibniz himself does not use this terminology, but he clearly wants to distinguish between mere changes of place, which are (completely) imaginary, and those changes of place that are grounded in force, that is, the real motions. Moreover, there are several texts from the correspondence with Arnauld in which the thing said to be relative is not simply motion but motion in itself,

${ }^{34}$ Jauernig, 'Leibniz on Motion'. 
apart from force. ${ }^{35}$ To put the point this way, though, is to imply that motion, insofar as it is grounded in force, is absolute. Such texts therefore support Jauernig's contention that motion at the merely phenomenal level is relative, while motion at the dynamical level is absolute.

Jauernig's approach does nevertheless suffer from one important defect. Like many scholars, she supposes that when Leibniz characterizes motion as relative, the kind of relativity he has in mind is relativity to a frame of reference. In other words, she understands him to be making the point that motion can properly be ascribed to a body only relative to a frame of reference. ${ }^{36}$ It seems to me, however, that this interpretation misconceives the point Leibniz wants to make in characterizing motion as relative. As I hope to show in what follows, his point is not the now-familiar thought that motion is relative to a frame of reference; in fact if I read him right, he doesn't consider motion relative in that sense at all. His point is rather that motion, unlike force, belongs to bodies not in and of themselves (i.e. absolutely), but only insofar as they relate to other things (i.e. relatively). That is, his point is that motion is what we would call a relational property, or what he might have called a relational accident or modification. Why this makes trouble for Jauernig's attempt to reconcile P2 and $\mathrm{R} 2$ will soon become clear.

The task of understanding Leibniz's talk of the relativity of motion is complicated by the fact that he never clearly explains what that relativity comes to; he typically just states that motion is relative and then proceeds without clarifying exactly what he means. A closer look at the texts does nonetheless turn up considerable evidence for my view. To begin with, there are several texts in which Leibniz indicates that motion's relativity has to do with it being a change of one body's position relative to other bodies. For instance, in the I689 essay on Copernicanism he notes that 'motion is in mathematical rigor nothing but a change in the positions of bodies among themselves,' and from this he immediately draws the conclusion that motion 'is not something absolute, but consists in a relation' (C 590/AG 9I). Similarly, in the Specimen dynamicum Leibniz

\footnotetext{
35 See Leibniz to Arnauld, I4 July I686, GP ii. 57/L 337; Leibniz to Arnauld, 28 November/8 December I686 (draft), A II. ii. II2; Leibniz to Arnauld, I4 January I688, GP ii. 133 .

${ }^{36}$ See Jauernig, 'Leibniz on Motion', I.
} 
criticizes Descartes for setting up his laws of motion as if motion were something absolute, as if he had forgotten that in defining motion as a body's change of position relative to its neighboring bodies, he was treating motion as something relative (GP vi. 247/AG I3O-I). ${ }^{37}$ To define motion, a modification, as a change of position relative to other bodies, however, is essentially to characterize it as a relational modification. So in calling motion relative Leibniz appears to be pointing out that motion is just such a modification. ${ }^{38}$

Even more significant is Leibniz's propensity for characterizing motion's relativity — as he does, for instance, in the passage just quoted from the essay on Copernicanism - as a matter of motion consisting in (or being) a relation. ${ }^{39}$ In order to appreciate the significance of this propensity, we must bear in mind that in Leibniz's idiolect the term 'relation' refers to two quite different kinds of entities: on the one hand something abstract which is neither a substance nor an accident but something ideal, and on the other something which is an accident belonging exclusively to just one subject. ${ }^{40} \mathrm{I}$ believe it would be safe to say that entities of the former sort correspond to what we tend to think of as relations proper, and those of the latter sort to what we would call relational properties (accidents, modifications). In describing motion as consisting in a relation, then, his point is either that motion is something ideal that has no subject, or that motion is a relational accident. Yet Leibniz clearly believes that motion must have a subject, since after all there can be no change of position without a changing subject. ${ }^{41}$ So when he claims that motion is a relation, it's unlikely that he has in mind the first kind of relation. Instead he must have the second kind in view.

${ }^{37}$ See Leibniz to Arnauld, 28 November/8 December I686 (draft), A II. ii. II2; essay on Copernicanism, C 590/AG 90 .

${ }^{38}$ Leibniz also claims that motion, like color and other sensible qualities, is not an 'absolute nature without relation to us' but 'something imaginary and relative to our perception' (Mira de natura substantiae corporeae, I683?, A VI. iv. I465/LOC 263; DM I2). On his view, then, the motion of a body involves not only a relation to other bodies, but a relation to perceivers, as we should expect given the status of motion as a phenomenon.

39 See, e.g. Specimen inventorum de admirandis naturae generalis arcanis, A VI. iv. I622/LOC 3I5; Spatium et motus revera relationes, A VI. iv. I968/LOC 225; essay on Copernicanism, C 590/AG 9I; Specimen dynamicum, GM vi. 248/AG I3I.

${ }_{40}$ For more on this, see GP vii. 40I/AG 339 and the discussion of this text in Dennis Plaisted, Leibniz on Purely Extrinsic Denominations (Rochester: University of Rochester Press, 2002), 7f. See also Leibniz to Des Bosses, 2i April I7I4, GP ii. 486/L 609.

${ }^{41}$ See Leibniz to Huygens, I2/22 June I694, A II. ii. 8Io/AG 308. 
His characterizations of motion as a relation therefore make the most sense if we take his point to be that motion is a relational modification.

What about those texts in which Leibniz connects the relativity of motion with the equivalence of hypotheses, including those in which he suggests that $\mathrm{P}_{2}$, the doctrine that motion is relative, implies $\mathrm{P}_{3}$, the doctrine that we cannot tell from a consideration of the phenomena which changes of place are the real motions (cf. §I.I)? Is it not clear that in these texts Leibniz is thinking of the relativity of motion as framerelativity? After all, on the supposition that he is, we can easily see why he thinks $\mathrm{P}_{2}$ implies $\mathrm{P}_{3}$. If motion is relative to a frame, or equivalently, to a hypothesis, it can only be because there is no correct hypothesis, that is, no hypothesis that correctly describes the real motions of bodies. But since there is a hypothesis for every possible assignment of motions to bodies consistent with the phenomena, there can evidently fail to be a correct hypothesis only if there are no real motions. And of course if there are no real motions, then we will never be able to tell which motions are the real ones. On this understanding of relativity, then, $\mathrm{P}_{2}$ clearly implies $\mathrm{P}_{3}$. The problem is that this isn't the only reasonable way to understand the connection between $\mathrm{P}_{2}$ and $\mathrm{P}_{3}$. Suppose the point of $\mathrm{P}_{2}$ is that the motion of a body is a relational modification in the sense that it involves a change of that body's position relative to other bodies. If so, then it follows from $\mathrm{P}_{2}$ that motion must be reciprocal, such that if any body $\mathrm{A}$ changes position relative to $\mathrm{B}, \mathrm{B}$ must also change position relative to $\mathrm{A}$. But this means that it will be impossible for us to tell just from a consideration of these changes of position which one if any is the real motion. Hence, $\mathrm{P}_{2}$ implies $\mathrm{P}_{3}$ even if understood along the lines I am proposing.

All things considered, the evidence for interpreting $\mathrm{P}_{2}$ as the claim that motion is frame-relative is rather weak. In contrast, the evidence for interpreting it as the claim that motion is a relational modification is considerable. ${ }^{42}$ Notice, however, that if we do interpret $\mathrm{P} 2$ as I am

\footnotetext{
${ }^{42}$ One other sort of text might be thought to count against my proposal. As I noted above, there are a few passages in the correspondence with Arnauld in which Leibniz implies that what is relative is not motion tout court, but only motion in itself, apart from force. If I am right about how to interpret $\mathrm{P}_{2}$, however, it follows that on Leibniz's view all motion is relative, since all motion, whether grounded in force or not, is a change of relative position. My response to this objection is that these texts may plausibly be interpreted in another way. It is true that in one of them he says simply that 'motion in itself, abstracted from its cause, is
} 
suggesting, then it can no longer be reconciled with $\mathrm{R}_{2}$ in the way proposed by Jauernig. The essence of her proposal was that $\mathrm{P}_{2}$ is true only of motion at the merely phenomenal level, whereas $\mathrm{R}_{2}$ is true only of motion at the dynamical level. But even motion at the dynamical level is a change of position relative to other bodies, and, therefore, a relational modification, albeit one grounded in force. Understood as the thesis that motion is a relational modification, then, $\mathrm{P}_{2}$ would be true of motion even at the dynamical level. And so the tension between $\mathrm{P}_{2}$ and $\mathrm{R} 2$ would reassert itself at the dynamical level. In order to resolve this apparent tension, we would need to employ some further strategy.

Fortunately we do not have to look far for such a strategy. Let us focus for the moment on R2, the thesis that motion is absolute. This is a doctrine we ascribe to Leibniz not so much because he states it, but because he commits himself to it in a rather straightforward fashion. But to which doctrine exactly does he commit himself? Is it that motion is an absolute or non-relational modification? Or is it that motion is 'frame-absolute', that is, not relative to a frame of reference? It seems clear that what he commits himself to is only the latter claim, not the former. Insofar as Leibniz believes that some changes of position are the real motions, he commits himself to the thesis that motion can be ascribed to bodies absolutely and not just within some frame. But he does not thereby commit himself to motion being a non-relational modification. Indeed there is no inconsistency in holding both that motion is frame-absolute and that motion is a relational modification. Suppose that bodies A and B move relative to one another, and that only A contains a force suitable to be the cause of its motion. Since A's motion is a change of position relative to $\mathrm{B}$, it is clearly a relational modification. But at the same time it's also frameabsolute, since $\mathrm{A}$ is really moving and not moving just relative to a frame. Hence, Leibniz does not commit himself to motion being

always something relative' (GP ii. 57/L 337). But in the others he puts the point in slightly different terms. He claims that 'all motion in itself is only a relative thing, namely a change of position' (GP ii. 69), and that 'motion in itself separated from force is only something relative [quelque chose de relatif seulement]' (GP ii. I33). These texts make it plausible to take Leibniz's thought to be not that only motion in itself is relative, but that motion in itself is only relative, that is, purely relative. That is, his point may be that whereas motion in itself is purely relative, motion together with force, as a mixture of the relative and the absolute, is not. 
a non-relational modification; he commits himself only to the thesis that motion is frame-absolute. And as we've just seen, the latter thesis is perfectly compatible with the doctrine that motion is a relational modification.

In view of these points, I conclude that the apparent inconsistency arising from Leibniz's acceptance of both $\mathrm{P}_{2}$ and $\mathrm{R}_{2}$ is an illusion. That appearance arises in the first place only because we find it natural to assume that when Leibniz speaks of the relativity of motion, the kind of relativity he has in mind corresponds to what we have in mind today when we speak of the relativity of motion. Upon closer examination, however, we can see that this assumption is flawed. Leibniz does accept that motion is relative, but only in the sense that it is a relational modification. At the same time, he considers motion to be absolute, but only in the sense that it isn't relative to a frame of reference. So on Leibniz's view motion turns out to be both relative and absolute, though not in a way that introduces any inconsistency.

\subsection{Leibniz's Considered View}

Bringing all these points together, we may say that though the phenomenalist approach (i.e. $\mathrm{P}_{\mathrm{I}}-\mathrm{P}_{4}$ ) and the realist approach (i.e. $\mathrm{R}_{\mathrm{I}}-\mathrm{R}_{4}$ ) both contain some truth, neither accurately captures Leibniz's thought about motion during the middle years. Instead, we ought to take his considered view during this period to consist in the following eight doctrines, each of which supersedes one of the original ones: ${ }^{43}$

(I) Motion itself is nothing but a change of position relative to other bodies. [supersedes $\mathrm{PI}_{\mathrm{I}}$ ]

(2) Motion, together with the force that causes it, is something more than just a change of position. [supersedes $\mathrm{R}_{\mathrm{I}}$ ]

(3) Motion, unlike force, is relative in the sense that it is a relational modification. [supersedes $\mathrm{P}_{2}$ ]

(4) Motion, like force, is absolute in the sense that it is not relative to a frame of reference. ${ }^{44}$ [supersedes R2]

${ }^{43}$ In fact I believe this continues to be his view until his death in I7I6, though I will not argue for that claim here.

${ }^{44}$ Note that on my reading this is a doctrine Leibniz accepts (and commits himself to), though not one he explicitly endorses as such. 
(5) We cannot determine from a consideration of motion itself which bodies are genuinely moving. [supersedes $\mathrm{P}_{3}$ ]

(6) We can determine from a consideration of motion together with its cause (i.e. force) which bodies are genuinely moving. [supersedes R3]

(7) Motion is an appearance or phenomenon, and so is not 'real' in the sense which contrasts with 'apparent'. [supersedes $\mathrm{P}_{4}$ ]

(8) Those motions grounded in force are real phenomena, and therefore real, but only in the sense of 'real' which contrasts with 'imaginary'. [supersedes R4]

In this section I have argued that we have strong textual grounds for replacing the original eight doctrines of the phenomenalist and realist approaches with these more nuanced, more carefully formulated claims. And these claims appear to form a perfectly coherent approach to motion. Despite appearances to the contrary, therefore, I conclude that Leibniz did indeed have a single coherent approach to motion throughout his middle years.

\section{CLASSIFYING LEIBNIZ'S VIEW}

It remains only to consider how this approach should be classified. In particular, was Leibniz a realist about motion during this stage of his development, as Levey has suggested? Or was he some kind of antirealist - a phenomenalist, perhaps, or even an idealist? Let us begin by observing that Leibniz can indeed be considered a kind of 'realist' about motion, since after all he does believe that some motion is real and not (completely) imaginary. However, we must be quick to add that this does not make him a realist in the sense of the term that scholars usually have in mind when they talk about realism in connection with Leibniz. What they tend to have in mind is something along the lines of the doctrine that entities in the relevant class (bodies, motions, etc.) enjoy a kind of mind-independent or perception-independent existence. To be a realist in this sense is to believe that the entities in question are real in the sense of 'real' which is opposed to 'apparent'. In this sense of the term, however, Leibniz is clearly not a realist about motion. Though he believes that some motion is real in the sense of 'real' which is opposed to 'imaginary', he also believes that motion, even real motion, is a phenomenon or appearance. So on his view motion is not real in the 
sense which is opposed to 'apparent'. Like phenomena in general, motion continues to be a perception-dependent feature of the world even when it has a foundation in something that exists independent of perception (i.e. force).

The Leibniz of the I680s and I69os, like the later Leibniz, is therefore most plausibly interpreted as a phenomenalist about motion. Does this mean that during this period he was a phenomenalist about the corporeal world in general? Not necessarily. Even if motion is only an appearance, it doesn't follow that the bodies that move are appearances. For all that I have shown here, Leibniz may well have held that bodies, together with their shapes and sizes, are real, perception-independent features of the world. ${ }^{45}$ Hence, we are not yet in a position to draw any conclusions about the status of the corporeal world in general in the metaphysics of Leibniz's middle years.

The question about idealism is a thornier one. If we take idealism about motion to be the view that motion is ultimately reducible to perceiving substances and their modifications, then during his middle years Leibniz was clearly an idealist about motion, since he held that motion is a phenomenon, and phenomena have their being in perceivers. In order for a view to count as an idealism about some class of entities, however, philosophers typically require that it involve not just a reduction of such entities to minds or perceivers, which might well be material, but a reduction of such entities specifically to that which is immaterial. ${ }^{46}$ Properly speaking, then, we are not yet in a position to say whether Leibniz was an idealist about motion. Though he clearly considered motion to be reducible to perceiving substances and their states, it remains to be seen what he thought during this period about the nature of these substances. On the one hand, he may have regarded them as immaterial, in which case he would undoubtedly rank as an idealist about motion. On the other hand, however, he may not have considered perceiving substances purely immaterial. As some have suggested, he may have viewed them as form-matter composites, in

${ }^{45}$ For a reading along these lines, see Garber, Leibniz, 297-9. According to Garber, the Leibniz of the middle years held that bodies are real, perception-independent beings, even though he was a phenomenalist about motion and the other 'primary' qualities of bodies.

${ }^{46}$ For more on the traditional understanding of Idealism, see Donald Rutherford, 'Leibniz as Idealist', Oxford Studies in Early Modern Philosophy, 4 (2008), I4I-90, esp. I4In.I. 
which case he would not have been an idealist, since he would have been reducing motion not to that which is immaterial, but to that which is a composite of the material and the immaterial. ${ }^{47}$ Until Leibniz's middle-years view of the nature of perceiving substances is clarified, therefore, we are not yet in a position to say whether he was an idealist about motion during this period. But we are in a position to say that he was a phenomenalist, and thus not, in the usual sense of the term, a realist. ${ }^{48}$

North Carolina State University

47 See Garber, Leibniz.

${ }^{48}$ For helpful feedback on previous versions of this paper, I would like to thank Dan Garber, Don Rutherford, Shane Duarte, two anonymous referees, and the audiences at the 2008 meetings of the Leibniz Society of North America, held at Princeton University, and the Southeastern Seminar in Early Modern Philosophy, held at Emory University. 